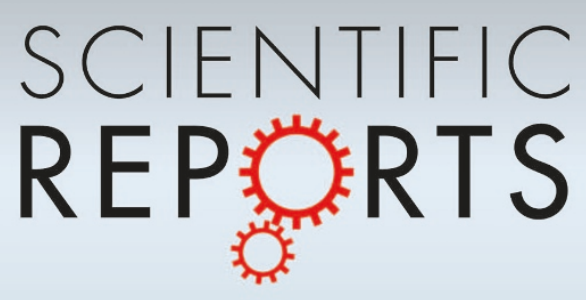

OPEN

SUBJECT AREAS:

ECOLOGY

ENVIRONMENTAL SCIENCES

MINERALOGY

ENVIRONMENTAL MONITORING

Received

22 May 2013

Accepted

26 February 2014

Published

27 March 2014

Correspondence and requests for materials should be addressed to

A.T. (turra@usp.br)

\section{Three-dimensional distribution of plastic pellets in sandy beaches: shifting paradigms}

\author{
Alexander Turra, Aruanã B. Manzano, Rodolfo Jasão S. Dias, Michel M. Mahiques, Lucas Barbosa, \\ Danilo Balthazar-Silva \& Fabiana T. Moreira
}

Oceanographic Institute, University of São Paulo, 05508-120, São Paulo, SP, Brazil.

Plastic pellets are worldwide contaminants that accumulate in the ocean, especially in sandy beaches, where their historic standing-stock quantification relies on surface sediment samples. We demonstrated these particles present a three-dimensional instead of a simple along-across shore distribution, being found as deep as $2.0 \mathrm{~m}$, with surface layers accounting for $<10 \%$ of the total abundance in the sediment column. This gradient seemed to be more related to oceanographic rather than anthropic processes, suggesting a general pattern whose applicability to microplastics and sedimentary environments as a whole should be investigated. This poses criticism in the exactness of standing-stock records and demands urgent discussion of sampling protocols.

lastic pollution is a major environmental concern in the ocean, and the impact of microplastics (particles < $5 \mathrm{~mm}$ ) has demanded special attention over the last years ${ }^{1-3}$. The total global production of plastics grew from 1.5 million tonnes in 1950 to 280 million tonnes in $2012^{1,4}$. This volume of production coupled with their durability and slow rate of biodegradation ${ }^{5}$ is correlated to extensive accumulation of plastic debris in terrestrial and aquatic habitats worldwide ${ }^{6}$. Recently, due to their broad and recognized threats, the classification for the most harmful plastics was proposed to be changed from solid to hazardous waste ${ }^{4}$.

Plastic resin pellets are large-sized microplastics, which are industrial raw material transported to manufacturing sites for production of a wide range of plastic products ${ }^{1,7}$. Resin pellets have being reported in marine waters worldwide and accumulate in depositional environments, including sandy beaches (e.g. $\left.{ }^{1,8,9}\right)$. Sources of pellets are both marine and land-based and include spillages during handling and transfer and losses during transportation, among others ${ }^{10}$.

Published reports so far have only explored the surface distribution of pellets and there is no available information on the in-depth occurrence of these contaminants in sandy beaches. Therefore, the goal of the current research was to provide an initial evaluation of the three-dimensional distribution of pellets in this environment. Exact and precise estimates of this pollutant are key indicators of the trends of this environmental problem. Here, we show that the standing stock of pellets in sandy beaches can be largely underestimated with surface sediment samples (e.g. ${ }^{9}$ ), as suggested by sampling protocols (e.g. ${ }^{11}$ ). We demonstrated that plastic pellets are consistently found distributed in-depth instead of just along and across-shore. We also identified the type of polymer composing the sampled pellets and evaluated a possible mechanism of deposition of pellets through the sediment column.

\section{Results}

Three-dimensional pellet distribution. The sampling done in Santos Bay (Brazil) to test the null hypothesis of uneven distribution of pellets in depth showed that the abundance of pellets decreased from the surface to the deeper strata, where pellets were concentrated. Although overall and pairwise differences could not be identified (ANOVA: $\mathrm{C}=0.15, \ln (\mathrm{X}+1), \mathrm{F}=2.79, \mathrm{df}=9, p=0.062$ ) due to the high values of standard error, two intermediate increases in abundances were observed at depth ranges of $20-40 \mathrm{~cm}$ and $60-70 \mathrm{~cm}$ (Fig. 1A).

Samples taken to test the null hypothesis of uneven distribution across-shore indicated that pellets were concentrated on the upper backshore (ANOVA: $\mathrm{C}=0.44(\mathrm{P}<0.01), \mathrm{F}=91.53, \mathrm{df}=11, p=0.00)$ and gradually decreased towards the upper beach intertidal limit where they were limited to the surface of the sedimentary column (Fig. 2). Due to the large variability among samples, especially in the upper strata (e.g. densities of pellets 

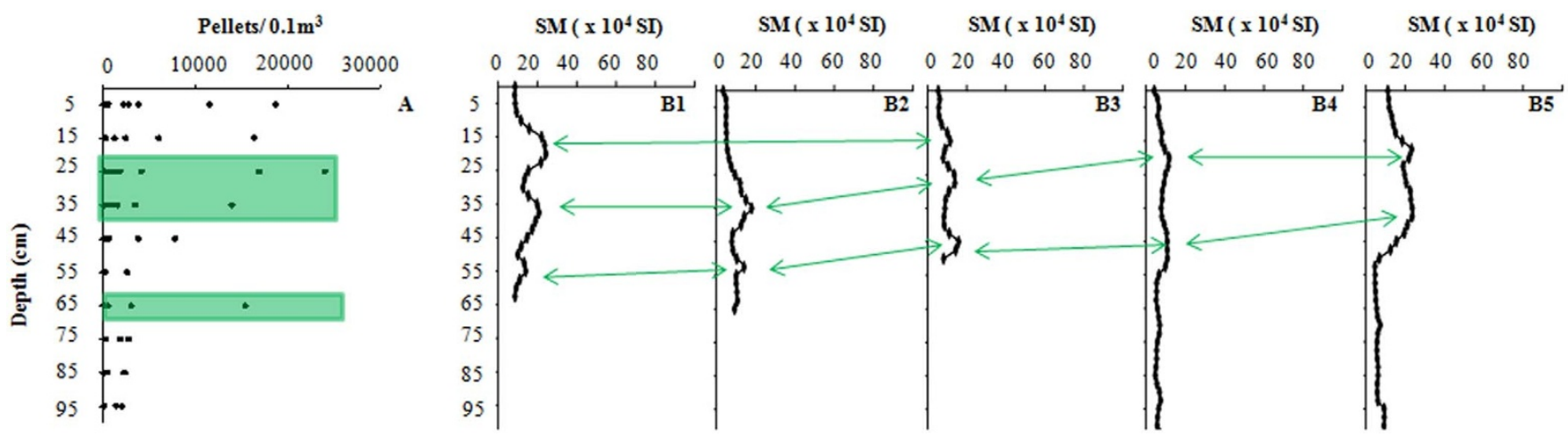

Figure $1 \mid$ Depth distribution of pellets and magnetic minerals in the sediment. (A) Number of pellets/0.1 $\mathrm{m}^{3}$ in the upper backshore at Santos Bay, Brazil $(n=10)$. (B1-B5) Deposits of heavy minerals (estimated using magnetic susceptibility values) in five vertical and equidistant sediment cores (analyzed every $2.5 \mathrm{~cm}$ ) taken from the upper (B1) to the lower (B5) backshore.

within each height of the shore ranged from 44 to 131 and 0 to 23), variances were heterogeneous and no transformation was able to stabilize variances.

The sampling done to test the null hypothesis on uneven distribution along-shore showed that the standing-stock of pellets was irregularly distributed (ANOVA: $\mathrm{C}=0.34(\mathrm{P}<0.05), \mathrm{F}=23.81$, $\mathrm{df}=14, p=0.00)$ and pellets were more abundant between the areas 2 to 6 (see Fig. 5), which are located at no more than $2 \mathrm{~km}$ from the entrance of the Santos port channel (Fig. 3). Nevertheless, pellets were found up to $2.0 \mathrm{~m}$ in depth, and their in-depth distribution along the bay followed the pattern of abundance observed at the surface (Fig. 3). A standing stock of approximately 762 million pellets was estimated to be present in the whole area.

To verify if in-depth distribution of pellets was consistent, i.e. being more abundant below the sediment surface, further sampling was done at three different beaches. In most of the sampled beaches, pellets were found vertically to a depth of $2.0 \mathrm{~m}$ and their abundance also decreased from shallow to deeper sediment layers, albeit with gradient differences among beaches (Fig. $4 \mathrm{a}-\mathrm{c}$ and Table I).

Identification of type of polymer. Results from the Ramam microscopy method for identification of a random sample of the type of

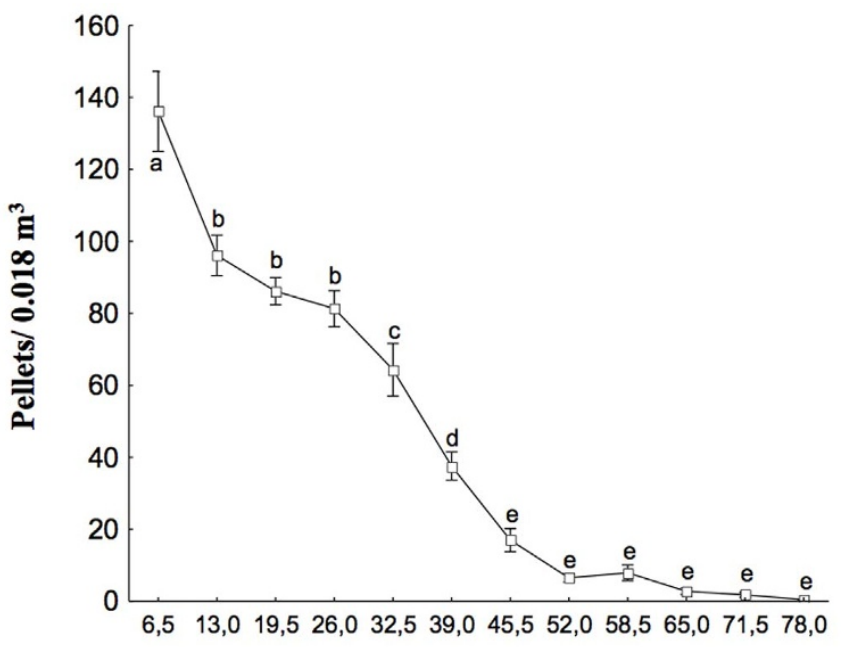

Distance across-shore (m)

Figure $2 \mid$ Abundance of pellets across-shore. Mean ( \pm SE) abundance of pellets $/ 0.018 \mathrm{~m}^{3}$ at each $6.5 \mathrm{~m}$ intervals across the beach. Letters on the error bars represent the results of the SNK test (similar letter denote not significant differences). Samples $(n=25)$ were taken from the upper backshore limit $(0 \mathrm{~m})$ to the high tide level $(78.0 \mathrm{~m})$ in Santos Bay (Brazil).

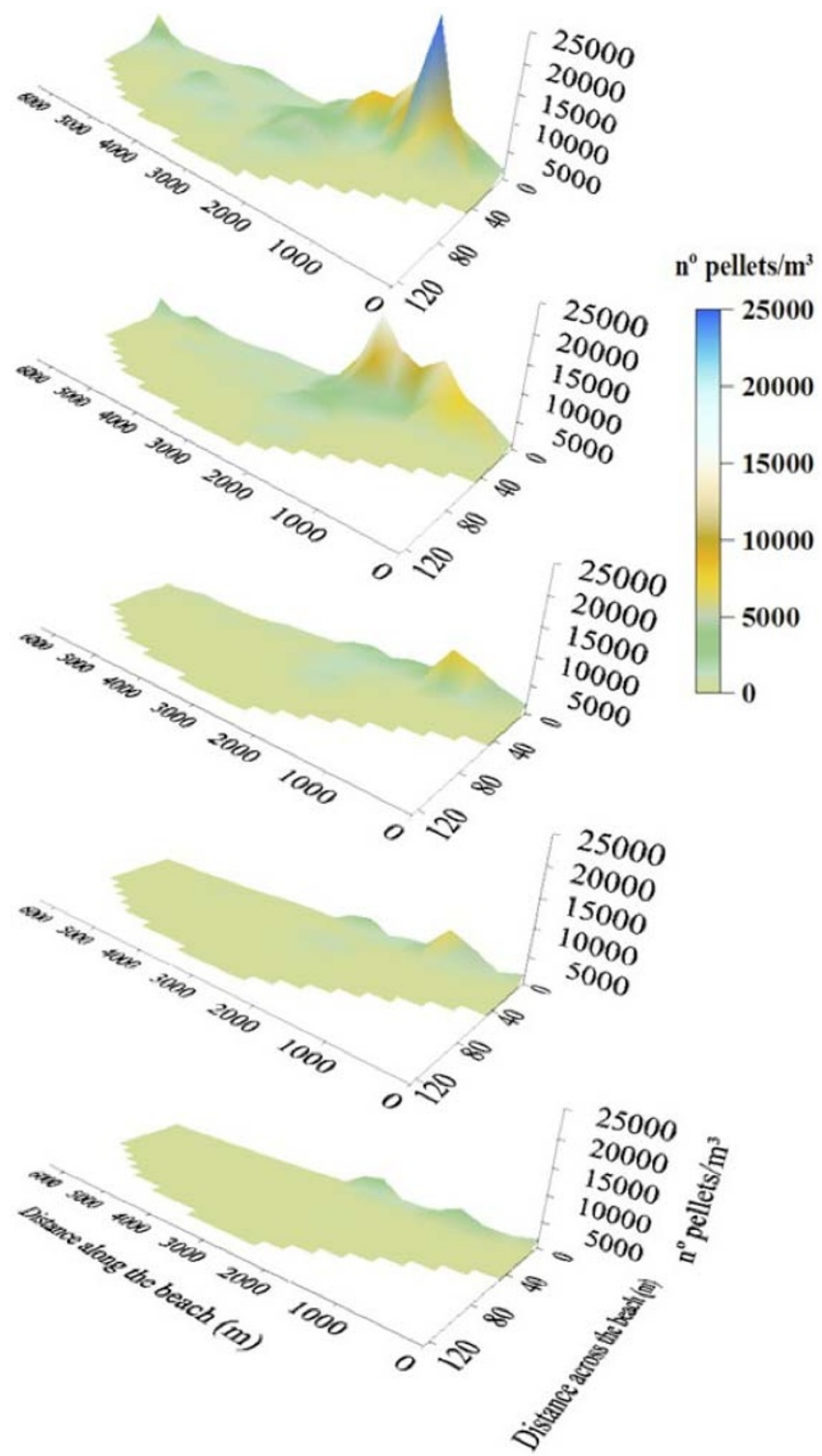

Figure $3 \mid$ Three-dimensional distribution of pellets in Santos Bay. Number of pellets per $1 \mathrm{~m}^{3}$ within five depth classes in the sediment $(0-0.4$, $0.4-0.8,0.8-1.2,1.2-1.6$ and $1.6-2.0 \mathrm{~m})$ in relation to the distances across $(n=10)$ and along shore $(n=15)$. 

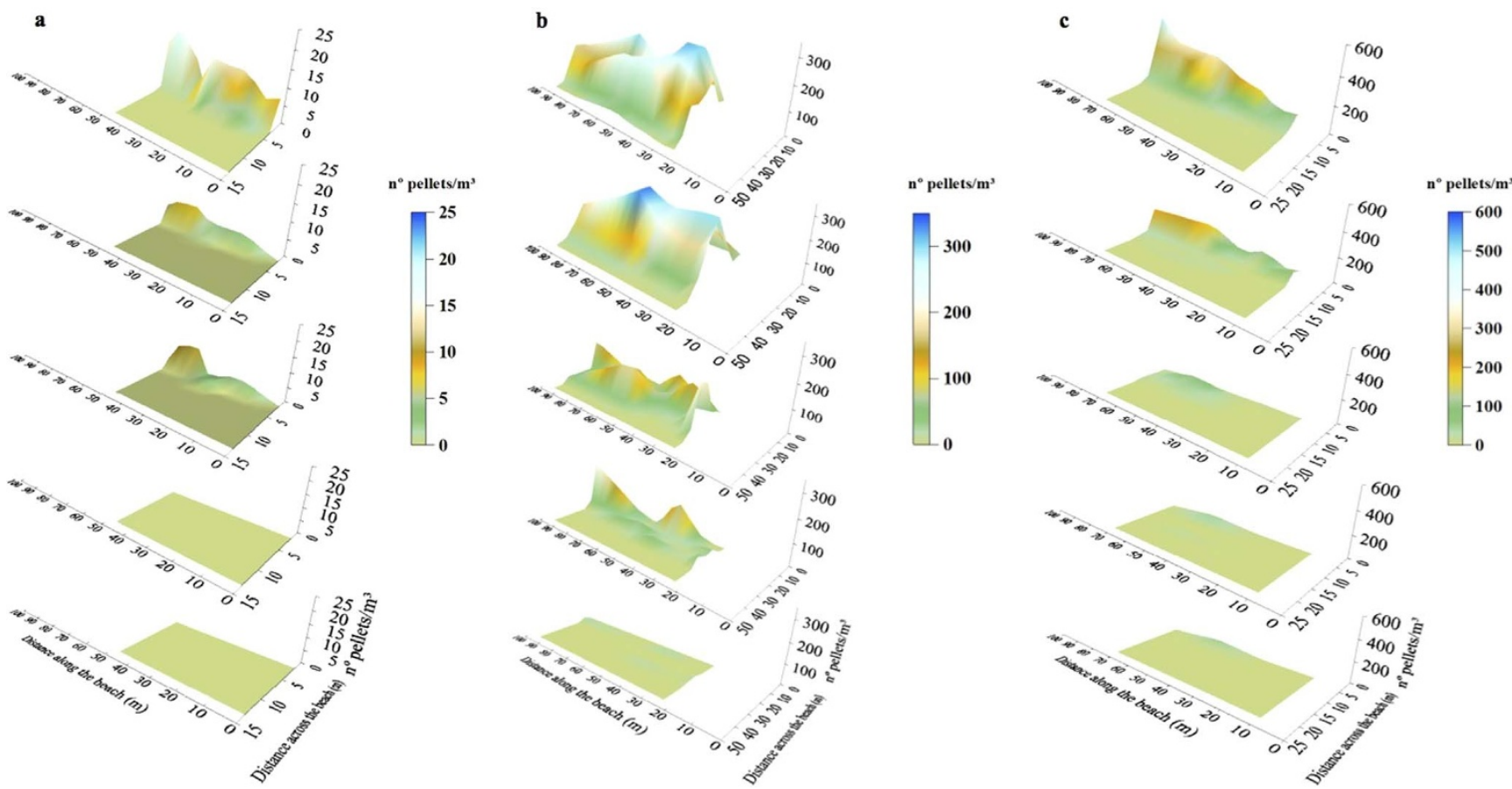

Figure $4 \mid$ Three-dimensional distribution of pellets in different beaches. Along-shore, across-shore and depth distribution of pellets $\left(\right.$ per $\left.1 \mathrm{~m}^{3}\right)$ in five depth classes in the sediment $(0-0.4,0.4-0.8,0.8-1.2,1.2-1.6$ and 1.6-2.0 m) in Felix (Ubatuba) (a), Enseada (Guarujá) (b) and Praia Grande Ubatuba (c) beaches, São Paulo State, Brazil.

polymer composing the pellets indicated that $18 \%$ were composed by polypropylene $(\mathrm{PP})(\mathrm{n}=90), 78.2 \%$ by polyethylene $(\mathrm{PE})(\mathrm{n}=391)$ and $3.8 \%$ were composed by a mixture of these two polymers $(\mathrm{n}=19)$.

Depth distribution of pellets and magnetic minerals in the sediment. The sediment column was clearly stratified with four wellpreserved layers and three peaks of heavy minerals found in the upper core (at $0.2 \mathrm{~m}, 0.35-0.40 \mathrm{~m}$ and $0.55 \mathrm{~m}$ depth; Fig. 1B1). The depths of these peaks became proportionally shallower towards the cores located closer to the seawater (Fig. 1B5). The first and third peaks in the upper corer (Fig. 1B1) were clearly related to the two in-depth peaks of pellets (Fig. 1A).
Comparisons with other works. Previous studies have recorded abundances of 1230 pellets $/ \mathrm{m}^{3}$ in Japan ${ }^{12}$ and 4666 pellets $/ \mathrm{m}^{3}$ in Hawaii $^{8}$ at a maximum depth of $0.055 \mathrm{~m}$. Nevertheless, if their sampling strategies would have included deeper sediments and the pattern of pellet in-depth distribution would be as in the present study, the density estimates could have reached 27214 pellets $/ \mathrm{m}^{3}$ (Table III) and 93891 pellets $/ \mathrm{m}^{3}$, respectively.

\section{Discussion}

The finding that there was a consistent greater concentration of the standing stock of pellets in areas deeper than the surface sediment demonstrates that the quantity of buried particles is important for

Table I | Depth distribution of pellets. Density $\left(\mathrm{m}^{3}\right)$ and percentage of pellets at different depths in the backshore of three beaches located in São Paulo State, Brazil and, specifically at $0.055 \mathrm{~m}$ for comparisons with other studies.

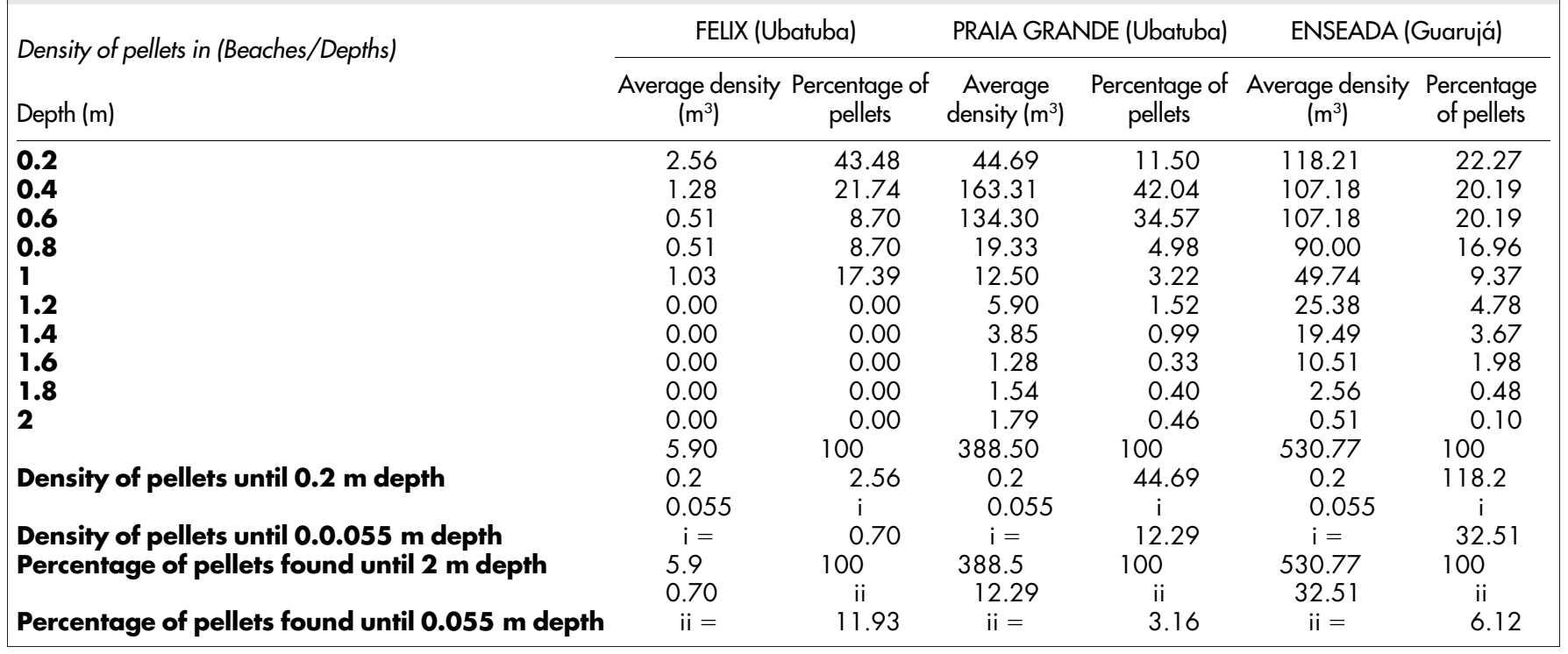


Table II | Densities of pellets in Santos Beach - São Paulo State, Brazil. Density $\left(\mathrm{m}^{3}\right)$ and percentage of pellets at different depths in the backshore and, specifically at $0.055 \mathrm{~m}$ for comparisons with other studies.

Density of pellets in Santos beach (area 3)

\begin{tabular}{|c|c|c|c|}
\hline Depth (m) & Average density $\mathrm{m}^{3}$ & Cumulative density & Percentage of pellets \\
\hline $\begin{array}{l}\text { Density of } \\
\text { Percentage }\end{array}$ & $5 \mathrm{~m}$ depth & $\begin{array}{c}0.2 \\
0.05 \\
i= \\
29775.79 \\
1346.27 \\
i i=\end{array}$ & $\begin{array}{c}5385.07 \\
\text { i } \\
\mathbf{1 3 4 6 . 2 7} \\
100 \\
\text { ii } \\
\mathbf{4 . 5 2}\end{array}$ \\
\hline
\end{tabular}

more exact estimates of the standing stock of pellets in sandy beaches. Using the data on vertical distribution of pellets taken at Santos to extrapolate the estimates from other works, it was possible to demonstrate that when abundance at deeper sediments is included, the estimates are much higher. Therefore, although estimates in the current published reports might be accurate, they may not representative of the beach standing stock if the in-depth pattern of pellet distributions recorded in the present study applies to these areas.

For studies addressing the standing stock of pellets and their environmental risk, having three-dimensional data seems therefore an advantage, as it may provide more exact estimates and understanding of the risk posed by these microplastics. Notwithstanding, further samplings in different beaches are still needed to get a better understanding of the variability in the abundance and in-depth distribution of pellets among beaches, which will contribute to a methodological discussion. Hence, for future estimation of the standing stock of pellets in sandy beaches it is suggested that samples should be taken until the depth of pellets occurrence, which may vary from beach to beach (e.g., maximum depth and/or density gradient) and influence the estimates (see Fig. 4 and Table I and II). It is also suggested the use of transects on the backshore and, to allow interpolation of data, that samples should be taken from equidistant heights. Additionally, replicated transects should be distributed along the beach.
As pellets are widely distributed and faster to evaluate in sediment samples, they were used in the current work as a model for microplastics. Although the three-dimensional distribution of pellets is known, their correlation to other microplastics, especially those with similar densities, still needs further investigation. If such correlation exists, it would be possible to use pellets to estimate the distribution pattern of other microplastics.

Moreover, as most of the published literature on microplastics concentration has not considered their distribution in depth, results are usually reported as number $/ \mathrm{m}$ or number $/ \mathrm{m}^{2}$. As we demonstrated that pellets are three-dimensionally distributed within the sediment column, it is also suggested that future works should be reported as number $/ \mathrm{m}^{3}$, which is a metric that is comparable with typical measurements of sediment quality.

This report also indicated that mechanisms of deposition of pellets through the sediment column might be related to oceanographic events, such as sea-storms. The stratified sediment column and the fact that the vertical distribution of heavy minerals strongly corresponded with peaks of pellet abundance indicate that pellets are concentrated at specific depths during high-energy oceanographic events and are not buried due to anthropogenic activities. The depth distribution of pellets might be related to differences in the exposure to extreme oceanographic events, as derived from this study, but also to temporal peaks and decreases in the production, transport and loss

Table III | Extrapolations to other works. Method used to extrapolate pellet concentrations in other manuscripts, based on the density found at $0.05 \mathrm{~m}$ depth in Santos Beach (Brazil). Example of calculations done to extrapolated data from other works

Example of extrapolation from Kusui \& Noda, 2003 (Japan)

\begin{tabular}{|c|c|}
\hline $\begin{array}{l}30616 \\
30616\end{array}$ & Total number of buried items \\
\hline $\mathrm{x}$ & Percentage of pellets among buried items \\
\hline$x=$ & Total number of pellets found in Japan \\
\hline $0.4 * 0.4 * 0.05$ & Volume sampled in one sampling point $\left(\mathrm{m}^{3}\right)$ \\
\hline 0.008 & Volume sampled in one sampling point $\left(\mathrm{m}^{3}\right)$ \\
\hline$n=56$ & Number of sampling points \\
\hline $0.008 * 56$ & $=0.448$ Total volume sampled in 56 sampling points $\left(\mathrm{m}^{3}\right)$ \\
\hline $551.09 / 0.448$ & $=1230.11$ Number of pellets $/ \mathrm{m}^{3}$ until $0.05 \mathrm{~m}$ depth \\
\hline $\begin{array}{l}\text { Number of pellets } / \mathrm{m}^{3} \\
1230.11\end{array}$ & $\begin{array}{l}\text { Percentage of pellets } \\
4.52\end{array}$ \\
\hline y & 100 \\
\hline$y=$ & 27214.82 Number of pellets $/ \mathrm{m}^{3}$ that would be found until $2 \mathrm{~m}$ depth \\
\hline
\end{tabular}


of pellets from nearby contamination sources (e.g. Cubatão city and Santos port in the present work), which could contribute to the variability in measurements of resin pellets in depth in a sandy beach. Further work is however needed to test these hypotheses.

It is important to notice that the hypothesis about a correlation between deposition of pellets and heavy minerals was raised only after the sampling and analyses of data which showed that pellets are distributed in-depth and there were peaks in there in abundances depending on the sampled depth. Therefore, the sampling for heavy minerals was not paired to the sampling done for pellets. Nevertheless, the study of minerals, even if not done in the exact location and same time, brings robust evidence of sediment stratification as a function of high energetic events, which may have an important role in the definition of the vertical structure of pellets in the sediment column. Further work is therefore needed to verify if that correlation corresponds to a real and broad pattern, preferentially using paired samples.

Plastic production is growing at approximately $8 \%$ per year, and the release of this ubiquitous contaminant into the ocean is expected to increase ${ }^{1}$. However, this trend is not reflected in the increasing abundance of floating microplastics (including pellets) ${ }^{3}$, which suggests that depositional areas, such as sandy beaches, may be the predominant fate of these materials. In fact, plastic debris may have economic, aesthetic and ecological impacts in the marine environment $^{2}$. The presence of small plastic fragments significantly increases the permeability of the sediment and sediment-containing plastic warms more slowly ${ }^{13}$, which may have a variety of potential effects on beach organisms. Moreover, additives used in the production of plastic goods can be toxic to aquatic organisms and plastics readily adsorb polychlorinated biphenyls (PCBs) and other organic pollutants from marine environments that can be transferred to organisms (e.g. $\left.{ }^{1,14}\right)$. Hence, in places where there is a high input of anthropogenic sources of contamination (sewage outlets and industrial outfalls), these contaminants can be also deposited in depth in sandy beach sediments, such as shown in Santos, where total PAHs were found in greater concentration between 30-40 and 60-70 cm $\operatorname{depth}^{15}$, where abundance of pellets was also greater. Therefore, the behavior of microplastics in the sediment column should be known so that adequate sampling strategies can be designed to test the hypothesis that depositional environments are the predominant sinks for pellets, and probably for microplastics as a whole, and to monitor their temporal trends.

The identification of the type of polymers composing pellets sampled in sandy beach sediment may be useful for further evaluation of the origin of those particles. Similarly to other works (e.g. ${ }^{16,17}$ ) our results indicated that polyethylene (PE) composed a greater proportion of the pellets sampled. Santos port may be the source of three types of polymers found in the sampled beaches, polypropylene (PP), high density (HDPE) and low density polyethylene (LDPE), through the handling of bags of pellets during the loading and unloading processes between trucks and ships. Some of the industries that are based in the region or that use the Santos port to export products are probably important contributors to the input of pellets in the sampled beaches. It is known that pellets composed by PP, HDPE, LDPE and also mixtures of PE and PP are produced and/ or exported in the region. The probable emissions along Santos Bay can be also originated from the washing process of holds and tanks of vessels, as pellets are a cheaper and lighter material than the sand. This information was given by local community and also reported in previous work (e.g. $\left.{ }^{16}\right)$. However, further work is needed to verify the above and other sources of pellets in the sampled region.

This report reveals that the standing stock of plastic pellets is distributed in three-dimensions in the sediment. This finding has broad implications to the current quantification of the standing stock of pellets in sandy beaches and further mitigation polices. In addition, considering that the upper sediment layers in sandy beaches are highly dynamic, being removed and deposited frequently by oceanographic events, the "shallow" estimates existing in the literature may not be exact nor reflect the history of contamination of a given area. This may, in part, explain the high variability observed on the microplastics distribution in many data sets worldwide ${ }^{18}$. This report also indicated that mechanisms of deposition of pellets through the sediment column might be related to oceanographic events, such as seastorms. Finally, more attention should be given to the way marine debris, especially microplastics, interacts with the environment to use them as indicators of environmental health.

\section{Methods}

Study areas. Samplings were done in beaches located in different municipalities in São Paulo State, Brazil (Fig. 5A and B), named São Vicente, Santos, Guarujá (Enseada beach) and Ubatuba (Praia Grande and Felix beaches) (Fig. 5C).

Santos is a highly urbanized city whose beaches receive an enormous number of visitors through the year. Santos estuary has the largest port in Latin America and is influenced by the intense industrial activity from the Cubatão city (refineries and petrochemicals), which is located less than $20 \mathrm{~km}$ inland and generates great concentrations of pellets, other solid residues and a range of chemical contaminants at the nearby beaches (Figure 1c). Santos and São Vicente beaches are periodically cleaned from solid waste by the city hall using different techniques that allow the removal of residues of the size of cigarette butts, but not smaller residues such as pellets and other microplastics.

Santos bay also has a system of ocean disposal of sewage, of a capacity of 5.3 thousand litres/second, which is in operation since $1978^{19}$. The system caters to most residences in Santos and half of the homes in São Vicente. As the system of ocean disposal of sewage attends only residences it was not considered as a possible source of pellets.

In the other municipalities, urbanization decreases with distance from Santos and population size fluctuates greatly around the year, with greater pressure in the summer and closer to Santos. Apart from Cubatão city and Santos Port there are no other nearby sources of pellets contamination. The city hall or local population also periodically cleans the beaches.

Coastal currents may influence the redistribution of pellets from the major sources to the nearby beaches. Both in winter and in summer, the dynamics of the ocean in the shelf region of São Paulo state is dominated by tides and wind forces; with strong bathymetric influence, tidal currents are weak and rotating in time (counterclockwise), with the major axis oriented approximately in the Northwest - Southeast direction (against the shore), while the currents generated by the prevailing winds are persistent and a little stronger, in the West - Southwest direction (parallel to the coast), turning to the East - Northeast direction (and generally more intense) under the influence of systems and wave fronts ${ }^{20-22}$.

Three-dimensional pellet distribution. Initial observations regarding the depth distribution of pellets were conducted using sediment collected in the upper backshore of the beaches at Santos Bay (Brazil, $23^{\circ} 56^{\prime} 27^{\prime \prime} \mathrm{S} ; 45^{\circ} 19^{\prime} 48^{\prime \prime} \mathrm{W}$ ).

To evaluate the depth distribution of pellets, the sediment was removed from $1 \mathrm{~m}^{2}$ trenches dug in the sand using a shovel. To ensure independence of datum, 100 trenches were dug and in each of them, a given depth (of $10 \mathrm{~cm}$ interval) was sampled. A total of 10 samples were taken at $0.1 \mathrm{~m}$ depth intervals until a depth of $1.0 \mathrm{~m}$. Pellets from each depth interval were separated by flotation in seawater and retrieved from the supernatant using a sieve ( $1 \mathrm{~mm}$ mesh size). Flotation was chosen as a method for separation of pellets to enable the sorting of the enormous number of samples taken during this study.

Analysis of variance (ANOVA) was used to test the null hypothesis that the abundance of pellets would be homogeneous across the different depths. The analysis considered the factor 'depth' (fixed, with 10 levels, $n=10$ ). Cochran's test for heterogeneity of variances was done prior to analyses and $\ln (\mathrm{X}+1)$ transformation was applied to the data to meet the analysis assumptions. Student-Newman-Keuls (SNK) tests were done for a posteriori comparisons within significant factors ${ }^{23}$. All analyses of variance were done using WinGMAV 5 (EICC, University of Sydney, Australia).

Pellet distribution across-shore was evaluated in an area $(50 \times 78 \mathrm{~m})$ that was divided into 12 equidistant heights across the shore. At each height, 25 sediment samples $\left(0.018 \mathrm{~m}^{3}\right)$ were randomly taken using a manual auger (diameter of 6 ") until a depth of $1.0 \mathrm{~m}$ was reached. The null hypothesis that pellets would be homogeneous distributed cross-shore was tested using ANOVA as before, considering the factor 'height of the shore' (fixed, with 12 levels, $n=25$ ).

The three-dimensional distribution (in-depth and across and along shore) of pellets was evaluated using 15 along-shore equidistant areas established in the backshore of Santos Bay (areas 1-10 correspond to beaches located in Santos, while areas 11-15 to beaches located in São Vicente)(Figure 5d). In each area, three transects were placed along a 20 -meter strip parallel to the waterline. These transects were sampled at 10 equidistant heights. Sediment $\left(0.036 \mathrm{~m}^{3}\right)$ was collected at 10 $0.2 \mathrm{~m}$ depth intervals until a depth of $2.0 \mathrm{~m}$ was reached. This sampling procedure generated 4500 sub-samples (e.g 15 along-shore areas $\times 3$ transects $\times 10$ heights $\times$ 10 depth intervals). These sub-samples were interpolated to generate an overall estimate for the total number of pellets/transect (IST, $\mathrm{see}^{24}$ ) and pellets $/ \mathrm{m}^{3}$ and were used to generate $3 \mathrm{D}$ graphs. ANOVA was used to test the null hypothesis that pellets 

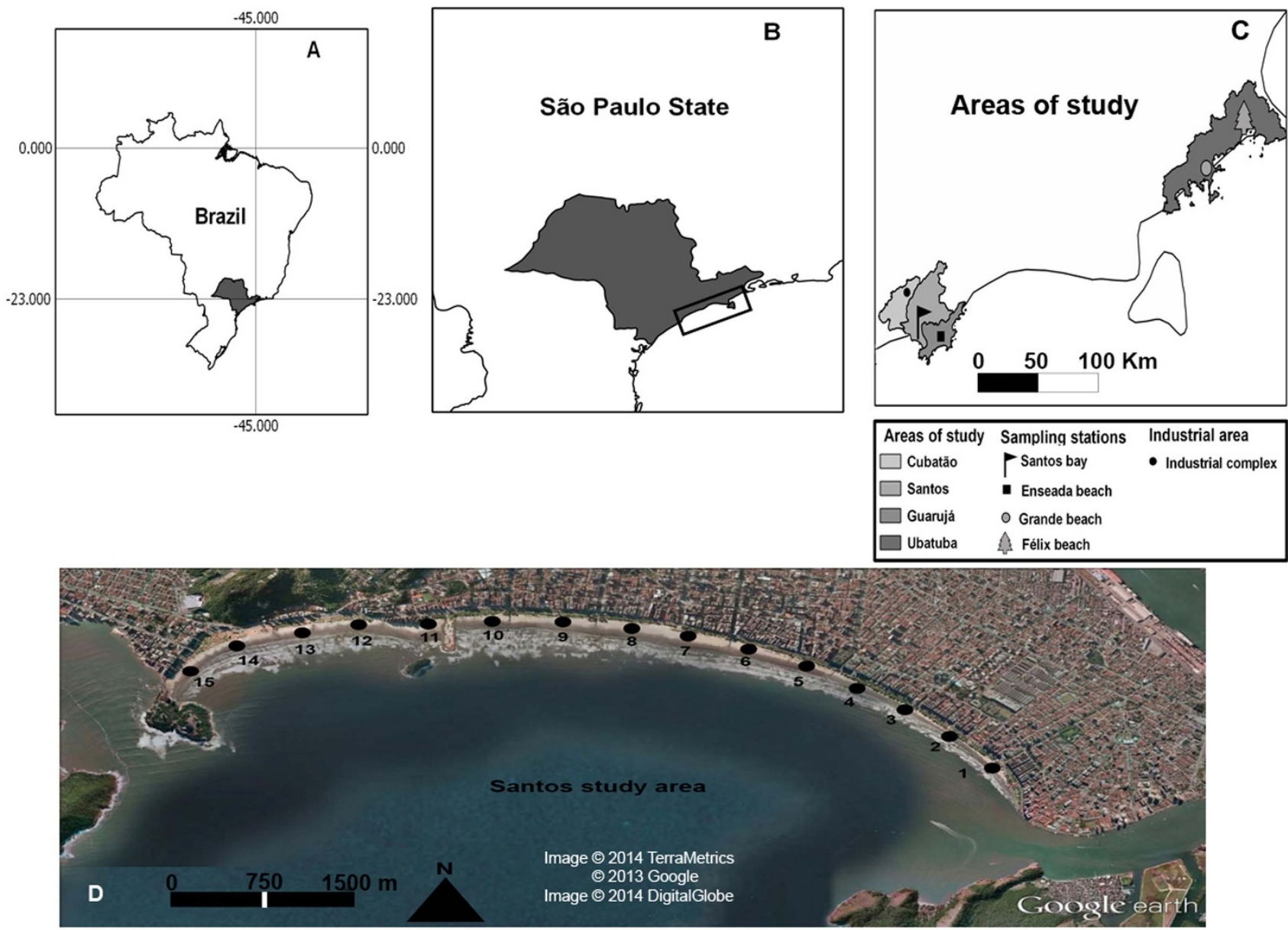

Figure $5 \mid$ The study area. (A) The Brazilian coast latitude and longitude. (B) Details of the coast of São Paulo State. (C) Location of sampled beaches (Santos, Enseada, Praia Grande and Felix) and possible sources of pellets (Santos and Cubatão). (D) Santos bay and details on the sampling design for the analysis of the three-dimensional distribution of pellets. The authors elaborated Figure 5. Contour maps of Brazil and the state of São Paulo were generated using the Quantum Gis 1.8.0. Software. For that, shapefiles were obtained at the site http://mapas.ibge.gov.br/bases-e-referenciais/basescartograficas/cartas. Figure 5D was acquired from Google Earth (Map data: Google, TerraMetrics and DigitalGlobe) and Quantum Gis was used to insert details (e.g. scale bar and symbols).

density $\left(\mathrm{m}^{3}\right)$ would be homogeneously distributed along-shore and therefore the factor 'area' (fixed, with 15 levels, $n=3$ ) was included. An estimate of pellet abundance for the entire study area was done by extrapolating the average number of pellets/transect $(0,15 \mathrm{~m}$ wide) to the linear beach length $(\mathrm{ca} .7500 \mathrm{~m})$. The crossshore distance where pellets were recorded (generally shorter than the backshore width and, consequently, the established transects) varied along-shore and was considered during the calculations to produce more conservative estimates of the standing stock than considering the entire lengths of each transect.

The vertical pellet distribution was further verified on the backshore of three additional beaches in São Paulo State (Brazil). These beaches were chosen to verify if pellets would be consistently distributed in depth, even considering beaches located at different distances from the major point source of contaminants (e.g. Cubatão city and Santos bay); from $10 \mathrm{~km}$ (e.g. Enseada beach $23^{\circ} 59^{\prime} 14.90^{\prime \prime} \mathrm{S} ; 46^{\circ} 13^{\prime} 50.30^{\prime \prime} \mathrm{W}$, located in Guarujá city) to more than $200 \mathrm{Km}$ (e.g. Praia Grande $23^{\circ} 46^{\prime} 62.40^{\prime \prime} \mathrm{S}$; $45^{\circ} 06^{\prime} 10.50^{\prime \prime} \mathrm{W}$ and Felix beaches) $23^{\circ} 23^{\prime} 21.44^{\prime \prime} \mathrm{S} ; 44^{\circ} 58^{\prime} 18.77^{\prime \prime} \mathrm{W}$, both located in Ubatuba city) (Figure 5C). In the dissipative and more depositional portion of each beach, a homogeneous area of $100 \mathrm{~m}$ was selected and five randomly chosen transects were sampled. In each transect, the sediment $\left(0.064 \mathrm{~m}^{3}\right)$ was taken until a depth of $2.0 \mathrm{~m}$, from 12 equidistant cross-shore heights.

Identification of type of polymer. The main purpose of this work was to evaluate the three-dimensional distribution of pellets as whole. Nevertheless identification of the type of plastic composing the pellets was done, as that information could be useful in further evaluations of the material origin. The chemical composition of 500 pellets was analyzed using the Ramam microscopy method ${ }^{25}$. Pellets were randomly chosen from the sampling done to evaluate the three-dimensional distribution of pellets. The measurements were done using a confocal Ramam microscope (WITec Alpha 300 R) with a laser light source (100 $\mathrm{mW}$ maximum potency) with a harmonic component at $1046 \mathrm{~nm}$ (50 mW maximum potency). For the acquisition of the Ramams' spectra, an area of approximately $0,5 \mu \mathrm{m} 2$ was used. Pellets were analyzed and grouped through comparisons of the spectra of the samples with those from standards of polypropylene (PE) and polyethylene (PP). It is important to notice that the separation of pellets from the sediment was done by the flotation method and only resins composed of PE or PP would float in seawater. Therefore, these were the two types of pellets that could be analyzed in the current work.

Depth distribution of pellets and magnetic minerals in the sediment. Heavy minerals may have magnetic properties depending on their physical and chemical composition; hence, their presence on sandy beaches can be used as indicators of high-energy oceanographic events (e.g. sea-storms ${ }^{26}$.

To verify the mechanism that may influence the in-depth deposition of pellets we evaluated the sediment stratification and the vertical distribution of heavy minerals, comparing it to the depth distribution of pellets. Using a $\operatorname{corer}^{27}$, five vertical samples of the sediment (up to $120 \mathrm{~cm}$ depth) were taken at each $20 \mathrm{~m}$ interval cross-shore, with the higher one located in the same area where the depth distribution analysis was conducted in Santos Bay. The sediment stratification was recorded and the amount of magnetic minerals was estimated via the values of magnetic susceptibility, measured by a MS2-C analyzer (Bartington, Oxon, England) at each $2.5 \mathrm{~cm}$ intervals.

Comparisons with other works. The distribution of pellets within the sediment column in Santos (area 3) was used to compare densities found in the current research to previous work, which were done at a maximum depth of $0.055 \mathrm{~m} \mathrm{(e.g.8,12).} \mathrm{For} \mathrm{that,}$ the cumulative density of pellets in Santos was calculated from the average density found at each $0.2 \mathrm{~m}$ depth, as well as their percentage of distribution at each $0.2 \mathrm{~m}$ depth until a depth of $2 \mathrm{~m}$ (Table II). The density of pellets until $0.055 \mathrm{~m}$ depth was then calculated by linear interpolation between 0 and $0.2 \mathrm{~m}$. Considering that in Santos 4.97 percent of the pellets were found until $0.055 \mathrm{~m}$ depth, rule of three method was then used to extrapolate the densities found in other works from $0.055 \mathrm{~m}$ to depth of $2 \mathrm{~m}$ (Table III). 
1. Ogata, Y. et al. International Pellet Watch: Global monitoring of persistent organic pollutants (POPs) in coastal Waters. 1. Initial phase data on PCBs, DDTs, and HCHs. Mar. Poll. Bull. 58, 1437-1446 (2009).

2. Thompson, R. C., Swan, S. H., Moore, C. J. \& vomSaal, F. S. Our plastic age. Phil. Trans. R. Soc. B. 364, 1973-1976 (2009).

3. Law, K. L. et al. Plastic Accumulation in the North Atlantic Subtropical Gyre. Science 329, 1185-1188 (2010).

4. Rochman, C. M. et al. Classify plastic waste as hazardous. Nature 494, 169-171 (2013).

5. Sudhakar, M., Doblea, M., Murthy, S. \& Venkatesan, R. Marine microbe-mediated biodegradation of low- and high-density polyethylenes. Int. Biodeterior. Biodegrad. 61, 203-213 (2008).

6. Derraik, J. G. B. The pollutionofthe marine environment by plastic debris: a review. Mar. Pollut. Bull. 44, 842-852 (2002).

7. Mato, Y. et al. Plasticres in pellets as a transport medium for toxicchemicals in the marine environment. Environ. Science \& Tech. 35, 318-324 (2001).

8. Carpenter, E. J., Anderson, S. J., Miklas, H. P., Peck, B. B. \& Harvey, G. R. Polystyrene spherules in coastal waters. Science 178, 749 (1972).

9. McDermid, K. J. \& McMullen, T. L. Quantitative analysis of small-plastic debris on beaches in the Hawaiian archipelago. Mar. Poll. Bull. 48, 790-794 (2004).

10. Turner, A. \& Holmes, L. Occurrence, distribution and characteristics of beached plastic production pellets on the island of Malta (central Mediterranean). Mar. Poll. Bull. 62, 377-381 (2011).

11. Cheshire, A. C. et al. UNEP/IOC Guidelines On Survey And Monitoring Of Marine Litter. UNEP Regional Seas Reports and Studies, No. 186; IOC Technical Series No. 83.xii + 120 pp (2009).

12. Kusui, T. \& Noda, M. International survey on the distribution of stranded and buried litter on beaches along the Sea of Japan. Mar. Poll. Bull. 47, 175-179 (2003).

13. Carson, H. S., Colbert, S. L., Kaylor, M. J. \& McDermid, K. J. Small plastic debris changes water movement and heat transfer through beach sediments. Mar. Poll. Bull. 62, 1708-1713 (2011).

14. Graham, E. R. \& Thompson, J. T. Deposit- and suspension-feeding sea cucumbers (Echinodermata) ingest plastic fragments. J. Exp. Mar. Biol. Ecol. 368, 22-29 (2009).

15. Fisner, M., Taniguchi, S., Moreira, F., Bícego, M. C. \& Turra, A. Polycyclic aromatic hydrocarbons (PAHs) in plastic pellets: Variability in the concentration and composition at different sediment depths in a sandy beach. Mar. Poll. Bull. 70, 219-226 (2013).

16. Pianowski, F. Resíduos Sólidos E Esférulas Plásticas Nas Praias Do Rio Grande Do Sul - Brasil. Fundação Universidade do Rio Grande, Departamento de Oceanografia, Rio Grande do Sul, 79 p. (1997).

17. Karapanagioti, H. K. \& Klontza, I. Investigating the properties of plastic resin pellets found in the coastal areas of Lesvos Island. Global Nest. J. 9, 71-76 (2007).

18. Kershaw, P. J. \& Leslie, H. (eds.) GESAMP Working group 40 - Sources, Fate \& Effects Of Micro-plastics In The Marine Environment - A Global Assessment: Report Of The Inception Meeting, 13-15 ${ }^{\text {th }}$ March 2012. UNESCO-IOC, Paris, 45pp. (2012).
19. Abessa, D. M. S., Imai, R. S. \& Harari, J. Toxicidade da água na Baía de Santos. In: Oceanografia e Mudanças Globais. Anais do III Simpósio Brasileiro de Oceanografia (ed. Braga, E. S.) São Paulo: IOUSP e FAPESP, p. 659-668 (2009).

20. Castro, B. M., Miranda, L. B. \& Miyao, S. Condições hidrográficas na plataforma continental ao largo de ubatuba: variações sazonais e em média escala. Bol. Inst. Oceanogr. 35, 135-151 (1987).

21. Castro, B. M. Correntes E Massas De Água Da Plataforma Continental Norte De São Paulo. Tese de Livre Docência. Universidade de São Paulo, São Paulo, 248 p. (1996).

22. Harari, J., Camargo, R., França, C. A. S., Mesquita, A. R. \& Picarelli, S. S. Numerical modeling of the hydrodynamics in the coastal area of Sao Paulo State - Brazil. J. Coastal Res. 39, 1560-1563 (2006).

23. Underwood, A. J. Experiments In Ecologoly: Their Logical Design And Interpretation Using Analysis Of Variance. Cambridge University Press Cambridge, 504pp (1997).

24. Defeo, O. \& Rueda, M. Spatial structure, sampling design and abundance estimates in sandy beach macroinfauna: some warnings and new perspectives. Mar. Biol. 140, 1215-1225 (2002).

25. Canevarolo, S. V. Técnicas De Caracterização De Polímeros. ArtLiber Editora Ltda. São Paulo, 448 p. (2004).

26. Komar, P. D., Clamens, K. E., Li, Z. \& Shi, S. The effects of selective sorting on factor analyses of heavy-mineral assemblages. J. Sediment. Petrol. 4, 590-596 (1989).

27. Mahiques, M. M., Toledo, C. V. \& Vilalta, L. E. Desenvolvimento de testemunhador a vibração portátil. Bol. Inst. Oceanogr. 37, 75-79 (1989).

\section{Acknowledgments}

We thank FAPESP (2007/51924-7) and CNPq (308124/2009-0) for research grants.

\section{Author contributions}

This study was conceived by A.T. Samples of sediment containing pellets and heavy minerals were taken by A.B.M., R.J.S.D., L.B. and D.B.-S. Analysis and interpretation of the data were completed by F.T.M., A.T., A.B.M. and M.M.M. The paper was written by F.T.M. and A.T.

\section{Additional information}

Competing financial interests: The authors declare no competing financial interests.

How to cite this article: Turra, A. et al. Three-dimensional distribution of plastic pellets in sandy beaches: shifting paradigms. Sci. Rep. 4, 4435; DOI:10.1038/srep04435 (2014).

(c) (i) $\Theta$ This work is licensed under a Creative Commons Attribution-

cc) visit http://creativecommons.org/licenses/by-nc-nd/3.0 